\title{
Effect of xanthohumol on Th1/Th2 balance in a breast cancer mouse model
}

\author{
WENCHAO ZHANG $^{1 *}$, YANLONG PAN ${ }^{1,2}$, PANHONG GOU $^{3 *}$ CHENG ZHOU $^{1}$, LIANQING MA ${ }^{4}$, \\ QIMING LIU ${ }^{4}$, YUPING DU ${ }^{1}$, JINBO YANG ${ }^{1}$ and QIN WANG ${ }^{1}$ \\ ${ }^{1}$ Institute of Cancer Biology and Drug Screening, School of Life Sciences, Lanzhou University; ${ }^{2}$ Center of \\ Scientific Experiments, Gansu University of Chinese Medicine; ${ }^{3}$ Institution of Toxicology, School of Public Health, \\ Lanzhou University, Lanzhou, Gansu 730000; ${ }^{4}$ Yumen Tuopu Science and Technology Development Co., Ltd., \\ Yumen, Gansu 735211, P.R. China
}

Received January 29, 2017; Accepted July 13, 2017

DOI: 10.3892/or.2017.6094

\begin{abstract}
Xanthohumol (XN), a prenylflavonoid found in the hop plant, Humulus lupulus, exhibits a variety of biological activities. Numerous studies have reported that XN inhibits the growth of many types of cancer cells, but the effects of XN on tumor immunity have not yet been studied. We explored the effect of XN on Th1/Th2 balance and the underlying mechanism based on a BALB/c-4T1 breast cancer mouse model. The results showed that $\mathrm{XN}$ significantly slowed down tumor growth and inhibited expression of antitumor proliferation protein $\mathrm{Ki}-67$ as well as breast cancer-specific marker cancer antigen 15-3 (CA15-3). Flow cytometric analysis revealed that $\mathrm{XN}$ enhanced the secretion of perforin, granzyme B and increased the ratio of $\mathrm{CD} 8^{+} / \mathrm{CD} 25^{+}$. ELISA analysis of cytokine results demonstrated that $\mathrm{XN}$ obviously upregulated Th1 cytokines, while downregulated Th 2 cytokines. Th1/Th2 ratio analysis by flow cytometry illustrated that $\mathrm{XN}$ regulated the balance drift to Th1 polarization. Western blotting and immunohistochemistry (IHC) results manifested that XN induced expression of T-bet, a Th1-specific transcription factor. Furthermore, we found that XN significantly promoted the phosphorylation of signal transducer and activator of transcription (STAT)4. Our results demonstrated that XN promoted Th1/Th2 balance towards Th1 polarization, and STAT4 may play a positive role in the regulation of Th1/Th2 cytokines by XN.
\end{abstract}

Correspondence to: Professor Qin Wang, Institute of Cancer Biology and Drug Screening, School of Life Sciences, Lanzhou University, 222 Tianshui South Road, Lanzhou, Gansu 730000, P.R. China

E-mail: qwang@lzu.edu.cn

*Contributed equally

Key words: xanthohumol, antitumor immunity, CTL responses, Th1/Th2 balance, STAT4

\section{Introduction}

Breast cancer is one of the most frequently diagnosed cancers, and is the second leading cause of cancer-related death in women, with an estimated 232,670 new cases identified and 40,000 deaths in the US alone in 2014 (1). Current therapies such as surgery, hormone therapy, chemotherapy, radiation therapy or complementary therapies are not always effective ways for fighting breast cancer, with some causing toxicities and unwanted effects. However, to the best of our knowledge, natural products have immune regulatory functions and less unwanted effects than chemical compounds. Studies have reported that natural products have regulatory actions in tumor immunity, such as activation of T lymphocytes, facilitation of the function of CTL and natural killer (NK) cell secretion of cytokines (2-4).

Xanthohumol (XN) is a prenylflavonoid found in hop plants (Humulus lupulus) (Fig. 1A), and has various biological properties. Previous epidemiologic studies have reported that $\mathrm{XN}$ reduces the risk of breast, prostate and pancreatic cancer (5-7). It can also decrease cell growth by inducing cycle arrest and apoptosis, which is dependent upon downregulation of Notch signaling pathway in hepatocellular carcinoma and human pancreatic cancer cells $(8,9)$, as well as inhibition of nuclear factor- $\kappa \mathrm{B}(\mathrm{NF}-\kappa \mathrm{B})$ activation (10). Nevertheless, to the best of our knowledge, there has been no study on $\mathrm{XN}$ and tumor immunity.

Helper $\mathrm{T}$ lymphocytes are in a core position with respect to tumor immunity. According to the type of cytokines secreted, they can be divided into mainly two subsets: Th1 and $\mathrm{Th} 2$, which differentiate from naive $\mathrm{T}$ lymphocytes (Th0) (11). Th1 effector cells produce characteristic cytokines interleukin (IL)-2, interferon (IFN)- $\gamma$ and tumor necrosis factor (TNF)- $\alpha$, which primarily mediate cellular immunity, including antitumor immunity. In addition, Th2 effector cells produce IL-4, IL-5, IL-6, IL-10 and IL-13, which mediate humoral immunity and promote antibody production (12). The Glimcher research team (Harvard University) isolated T-bet (T-box protein expressed in T cells), a Th1-specific transcription factor involved in Th1 differentiation and transformation, in 2000 (13). GATA-binding protein-3 (GATA-3) belongs to 
A

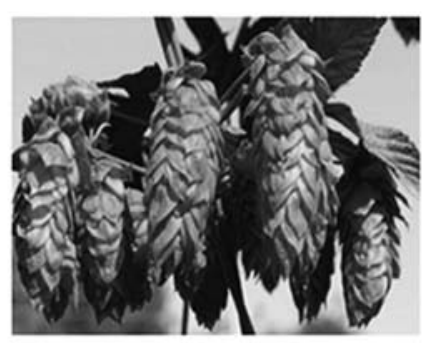

B

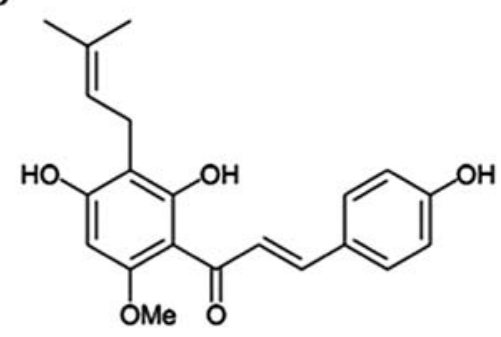

$\mathrm{C}$

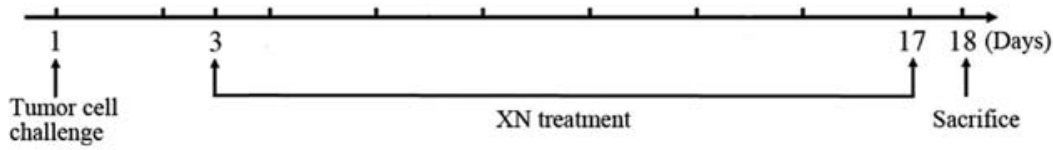

Figure 1. Drug and treatment schedule. (A) Image of hops. (B) Chemical structure of xanthohumol (XN). (C) Treatment schedule in the present study.

the GATA family transcription factors and is a zinc-finger DNA binding protein. It is a Th2-specific transcription factor and is involved in Th2 differentiation and transformation (14). Furthermore, it is particularly notorious that $\mathrm{T}$ cells express GATA-3 through two pathways, which are both dependent on STAT6. However, there are different modes of activation of STAT6: one is auto-activation (15), and the other is activated by IL-4 and T cell receptor (TCR) in co-simulation (16). Recent research has shown that $\mathrm{T}$ cells also express T-bet through two pathways, one is dependent on STAT4, which is activated by IL-12, and the other is dependent on STAT1, which is activated by IFN- $\gamma$ (17). Under normal circumstances, Th1 and Th2 cytokines maintain a relative balance, which is important for maintenance of immune equilibrium. However, when dysfunction occurs, the balance is disturbed, known as 'the shifting of Th1/Th2 balance' (18). In addition, this may cause different types of diseases, such as cancer (19-21), AIDS (22) and autoimmune diseases (23). When the balance drifts from Th1 to Th2, it may cause antitumor immunosuppression (24).

Our previous research suggested that $\mathrm{XN}$ inhibits breast cancer cell survival via modulating the Notch signaling pathway in vivo and in vitro (25). Meanwhile, preliminary test results demonstrated that $\mathrm{XN}$ enhanced expression of T-bet and weakened expression of GATA-3. These results led us to believe that XN exerts various effects on Th1/Th2, and we explored the underlying effects in the present study.

\section{Materials and methods}

Reagents and antibodies. XN (purity $>98.6 \%$ ) was provided by Yumen Tuopu Science and Technology Development LLC (Yumen, China), in accordance with the chemical structure of $\mathrm{XN}$ as shown in Fig. 1B. Anti-mouse CD3 (FITC), anti-mouse CD4 (PE), anti-mouse CD8 (PE), anti-mouseCD25 (APC), anti-mouse IL-4 (APC), anti-mouse IFN- $\gamma$ (DAPI), anti-mouse perforin (FITC), anti-mouse granzyme B (FITC), flow cytometry staining buffer, fixation/permeabilization concentration, fixation/permeabilization diluent and permeabilization buffer were purchased from eBioscience, Inc. (San Diego, CA, USA). Mouse IL-2, mouse IL-4, mouse IL-10 and mouse IFN- $\gamma$ ELISA kits were purchased from Elabscience Biotechnology Co., Ltd.
(Wuhan, China). Anti-T-bet and anti-GATA-3 antibodies were purchased from Abcam (Cambridge, UK). Ki-67 (D3B5) was purchased from Cell Signaling Technology (CST; Boston, MA, USA). Anti-phospho-STAT4 (Tyr693), anti-STAT4, antiSTAT6, and anti-phospho-STAT6 (Tyr641) were purchased from Biosynthesis Biotechnology Co., Ltd. (Beijing, China). Total protein extraction kit was purchased from BestBio Co., Ltd. (Shanghai, China). Mouse 1X lymphocyte separation medium was purchased from Dakew (Shenzhen, China).

Cell line and animals. The 4T1 cell line was purchased from the China General Microbiological Culture Collection Center (Shanghai, China). The 6- to 8-week-old BALB/c female mice, weighing $18 \pm 2 \mathrm{~g}$, were purchased from Lanzhou Veterinary Research Institute (Chinese Academy of Agricultural Sciences, Lanzhou, China). All the animals were acclimatized for one week. Living environment was maintained under controlled conditions $\left(24 \pm 2^{\circ} \mathrm{C}, 50 \pm 10 \%\right.$ relative humidity, with a rhythm of $12 \mathrm{~h} \mathrm{light/dark} \mathrm{cycles).}$

Treatment of mice. All animal methods in the experiments were in line with 'Guidelines for the Humane Treatment of Laboratory Animals', which was issued by the Ministry of Science and Technology of the People's Republic of China in 2006.

Mice were randomly assigned into five groups and named the healthy, control, $25 \mathrm{mg} / \mathrm{kg} \mathrm{XN}$ and $50 \mathrm{mg} / \mathrm{kg} \mathrm{XN}$ groups, and $10 \mathrm{mg} / \mathrm{kg}$ cyclophosphamide (Cy) group. Cy has been reported to shift Th1/Th2 immune response from Th2 to Th1 (26,27); we used it as a positive treatment. A mouse model of breast cancer was constructed by subcutaneous injection of $4 \mathrm{~T} 1$ cells $\left(1 \times 10^{5}-10^{6}\right.$ cells $\left./ \mathrm{ml}\right)$ into the right posterior leg. Drugs and solvent were administered by gavage after three days of injection, and treatment was administered for two weeks. The healthy and control groups received only solvent. The treatment schedule is shown in Fig. 1C. Two weeks later, mice were anesthetized with ether and peripheral blood was collected by removal of the eyeballs. Finally, tumors and spleens were removed from the mice.

Calculation of the tumor volume (V) was as follows: $\mathrm{V}_{\text {tumor }}=\left(\mathrm{L} \mathrm{x} \mathrm{W}^{2}\right) / 2(\mathrm{~L}$, is the longest diameter; $\mathrm{W}$, is the shortest 
diameter) (28), and the diameters were measured by electronic calipers. Tumor inhibitory rate $=$ (tumor weight of treatment group - tumor weight of control group)/tumor weight of control group $\mathrm{x} 100 \%$. Rate of body weight change $=($ body weight at the end of experiment - body weight at the beginning of experiment)/body weight at the beginning of experiment $x 100 \%$. The above experiments were performed at least three times.

Western blot analysis. We homogenized the tumor tissues and obtained total protein using a total protein extraction kit. Sodium dodecyl sulfate-polyacrylamide gel electrophoresis (SDS-PAGE) (12\%) was performed on $30 \mu \mathrm{g}$ of each sample protein, and then the samples were transferred to polyvinylidene difluoride membranes (Millipore, Bedford, MA, USA). Blocking of non-specific protein occurred at room temperature in Tris-buffered saline-Tween-20 (TBST; TBS containing $0.01 \%$ Tween-20)-5\% non-fat milk. Following incubation with the primary antibody at $4^{\circ} \mathrm{C}$ overnight, incubation with the secondary antibody was carried out at room temperature for $4 \mathrm{~h}$. Membranes were washed with TBST for $5 \times 5 \mathrm{~min}$ and peroxidase activity was visualized with an enhanced chemiluminescence western detection system (Perkin-Elmer Life Sciences, Boston, MA, USA).

Immunohistochemistry (IHC) and histopathologic analysis. Tumor tissues $(3 \mu \mathrm{m})$ were cut and fixed in formalin buffer after being paraffin-embedded. Paraffin-embedded cancer tissue sections were deparaffinized and dewatered first. Then, slides were incubated with $0.3 \% \mathrm{H}_{2} \mathrm{O}_{2}$ for $10 \mathrm{~min}$ and washed with $\mathrm{ddH}_{2} \mathrm{O}$ for $3 \times 3 \mathrm{~min}$. Antigen retrieval was undertaken in a pressure cooker for $10 \mathrm{~min}$ with $0.01 \mathrm{M}$ citrate buffer and washed with phosphate-buffered saline (PBS) for $3 \times 5 \mathrm{~min}$. Bovine serum albumin (BSA) (5\%) was applied to the specimen sections to block non-specific protein for $20 \mathrm{~min}$ at room temperature. The primary antibody was incubated for $2 \mathrm{~h}$ at $37^{\circ} \mathrm{C}$ and washed with PBS for $3 \times 3$ min. After washing, specimen slides were incubated with the secondary antibody for $20 \mathrm{~min}$ at $37^{\circ} \mathrm{C}$ and washed with PBS for $3 \times 3 \mathrm{~min}$. Finally, the specimen slides subsequently underwent 3,3'-diaminobenzidine (DBA) staining for $10 \mathrm{~min}$. Slides were assessed using microscopy; positive cells are shown in brown or yellow and cell nuclei are shown in blue.

Flow cytometric analysis. The spleen from each sacrificed mouse was aseptically removed and put into a 35-mm culture dish containing cold PBS. Total lymphocytes were separated using the Mouse 1X Lymphocyte Separation Medium. Then, the lymphocytes were resuspended at a concentration of $1 \times 10^{7}$ cells $/ \mathrm{ml}$ and transferred $(100 \mu \mathrm{l})$ to a $1.5 \mathrm{ml}$ tube. The antibody was then labeled. For the Th1 and Th2 subset analysis, Th1 subsets were labeled as $\mathrm{CD} 3{ }^{+} \mathrm{CD} 4{ }^{+} \mathrm{IFN}-\gamma^{+}$, Th2 subsets were labeled as $\mathrm{CD}^{+} \mathrm{CD} 4^{+} \mathrm{IL}^{+}{ }^{+}(29,30)$. The ratio of $\mathrm{Th} 1 / \mathrm{Th} 2=$ percentage of $\mathrm{CD} 4^{+} \mathrm{IFN}-\gamma^{+} /$percentage of CD $4{ }^{+} \mathrm{IL}_{4}{ }^{+}$. Cell surface antigens CD3 and CD4 were labeled in the dark for $30 \mathrm{~min}$. Then, cells were fixed and permeabilized in fixation/permeabilization mixture in dark for $1 \mathrm{~h}$. Lastly, the anti-mouse IFN- $\gamma$ and IL4, which are intracellular antigens, were incubated in the dark for $30 \mathrm{~min}$. For the perforin and granzyme B subset analysis, splenic lymphocytes were fixed and permeabilized first, and then the anti-mouse perforin and
Table I. Effects of XN on body weight and tumor growth in the BALB/c-4T1 mice.

\begin{tabular}{lcccc}
\hline $\begin{array}{l}\text { Dose } \\
(\mathrm{mg} / \mathrm{kg})\end{array}$ & $\begin{array}{c}\text { No. of } \\
\text { mice }\end{array}$ & $\begin{array}{c}\text { Tumor } \\
\text { weight } \\
(\mathrm{g})\end{array}$ & $\begin{array}{c}\text { Inhibitory } \\
\text { rate } \\
(\%)\end{array}$ & $\begin{array}{c}\text { Rate of body } \\
\text { weight change } \\
(\%)\end{array}$ \\
\hline 0 (Healthy) & 11 & - & - & +6.01 \\
0 (Control) & 11 & $0.732 \pm 0.21$ & - & +1.20 \\
$25 \mathrm{XN}$ & 10 & $0.544 \pm 0.23$ & 25.68 & +2.96 \\
$50 \mathrm{XN}$ & 10 & $0.456 \pm 0.22$ & 37.72 & +1.90 \\
$10 \mathrm{Cy}$ & 10 & $0.514 \pm 0.21$ & 29.85 & -0.93
\end{tabular}

Calculation methods for tumor inhibition rate and body weight change are provided in Materials and methods. XN, xanthohumol.

granzyme B antibodies, which are also intracellular antigens, were incubated in the dark for $30 \mathrm{~min}$. For the CD8 and CD25 subset analysis, the $\mathrm{CD} 8$ subset was labeled as $\mathrm{CD} 3{ }^{+} \mathrm{CD} 8^{+}$, and the $\mathrm{CD} 25$ subset was labeled as $\mathrm{CD} 3{ }^{+} \mathrm{CD} 25^{+}$. After antibodies were labeled, lymphocytes were fixed in $1 \%$ paraformaldehyde, and detected by flow cytometer. The above procedures were performed on ice and repeated at least three times.

ELISA analysis. Serum was separated from peripheral blood via centrifugation $\left(12,000 \mathrm{rpm}, 10 \mathrm{~min}, 4^{\circ} \mathrm{C}\right)$ and stored at $-20^{\circ} \mathrm{C}$. Four cytokines (IL-2, IL-4, IL-10 and IFN- $\gamma$ ), and the key tumor-specific markers (CA15-3) were detected using mouse cytokines ELISA kit. All steps were followed in accordance with the manufacture's protocol. The cytokines and marker were detected within seven days after serum separation, and above procedures were performed on ice and repeated at least three times.

Statistical analysis. Values are presented as mean \pm standard deviation (SD) and analyzed by one-way analysis of variance (ANOVA) using GraphPad Prism 5. The results of flow cytometry were analyzed using FlowJo 7.6.1. Grayscale quantitative analysis was performed using Image Pro-Plus 6.0. Probability values $<0.05$ were considered to indicate statistical significance.

\section{Results}

$X N$ inhibits breast cancer growth in a mouse model. Body weight, tumor volume and tumor weight were assessed to evaluate the effects of $\mathrm{XN}$ on breast cancer. As shown in Fig. 2A and B, the tumor growth of the $\mathrm{XN}$-treated groups was evidently slower than that noted in the control group. Fig. 2D shows that tumor weight was significantly decreased in the $50 \mathrm{mg} / \mathrm{kg}$ XN-treated group compared with the control group $(\mathrm{p}=0.036)$. Meanwhile, Table I shows that inhibitory rate of tumor growth in the 25 and $50 \mathrm{mg} \mathrm{XN}$ groups and Cy-treated group was $25.68,37.72$ and $29.85 \%$, respectively. Body weight did not obviously change in the four groups (Fig. 2C), while $10 \mathrm{mg} / \mathrm{kg}$ Cy caused negative growth rate (-0.93\%) (Table I).

$X N$ inhibits the expression of $\mathrm{Ki}-67$ and $\mathrm{CA15-3}$ in the mouse model. CA15-3 and antigen Ki-67 are the most common 
A

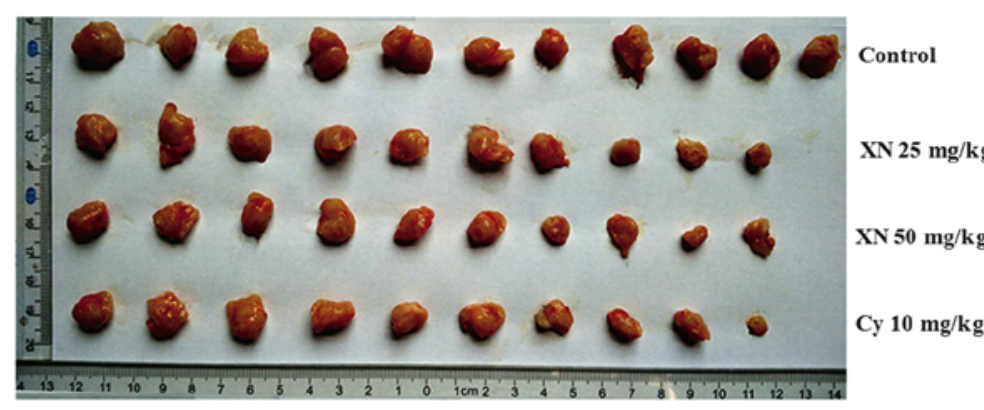

C

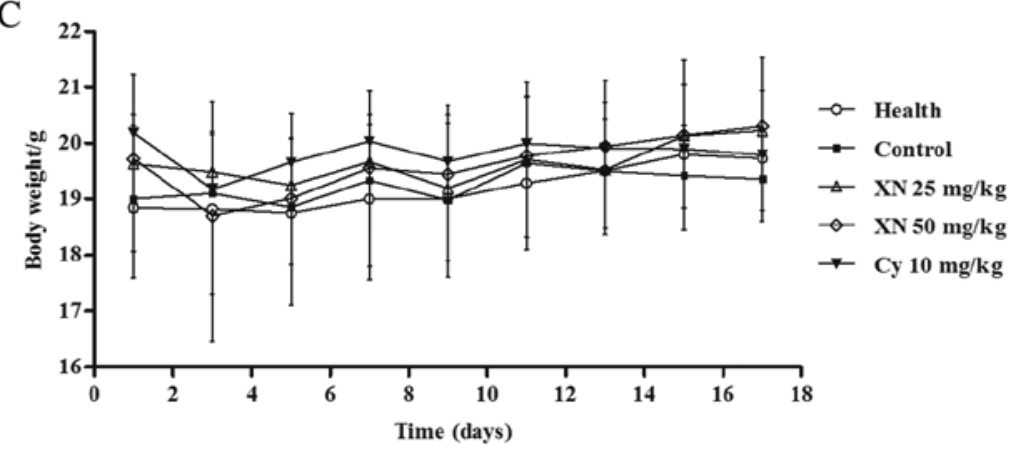

B

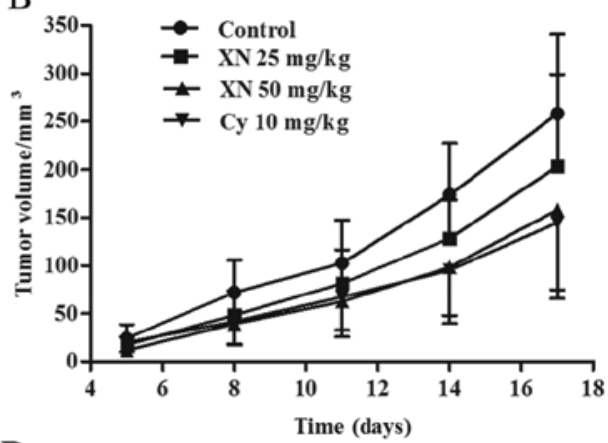

D

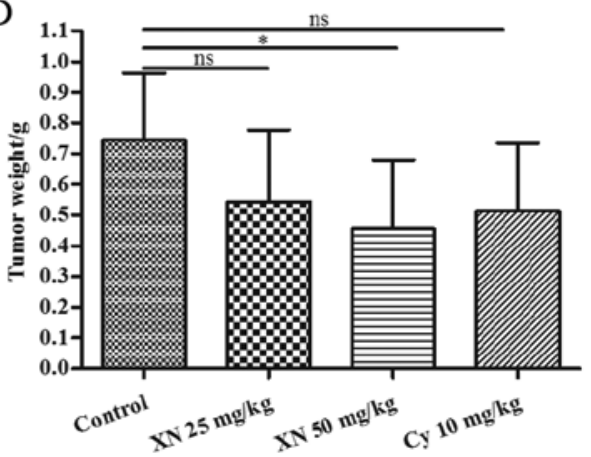

Figure 2. Effect of xanthohumol (XN) on tumor growth and progression in the mouse model. (A) Tumors from BALB/c-4T1 tumor-bearing mice under different treatment conditions. (B) Changes in tumor volume during the experiment. (C) Curves of body weight during the experiment. (D) Histogram of tumor weight at the end of the experiment. ${ }^{*} \mathrm{p}<0.05$; ns, not significant.
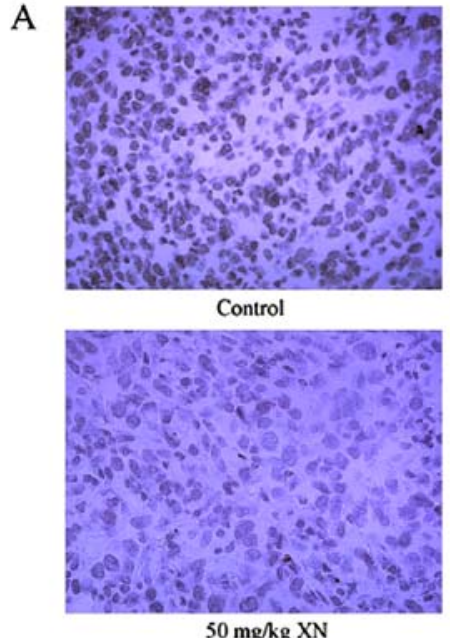
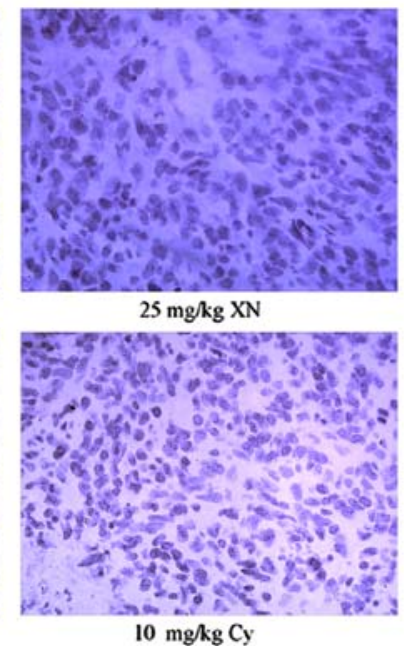

B

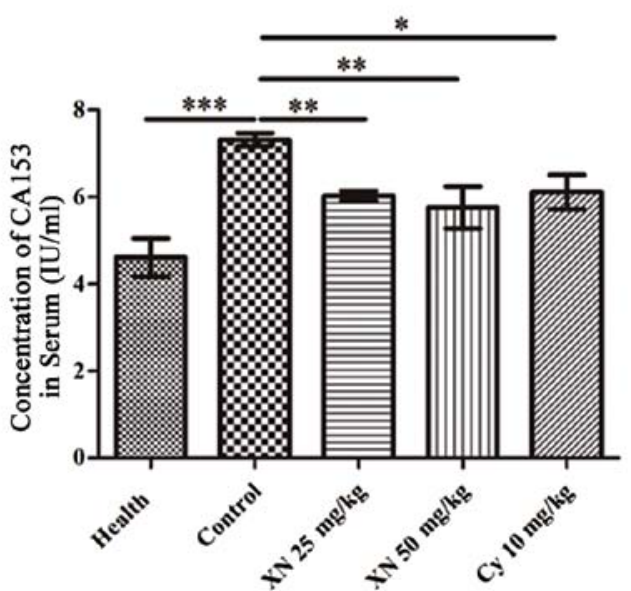

Figure 3. Effect of xanthohumol (XN) on breast cancer markers in the mouse model. (A) IHC of Ki-67 in tumor tissue (magnification, x20). (B) Levels of CA15-3 in serum. ${ }^{*} \mathrm{p}<0.05,{ }^{* *} \mathrm{p}<0.01,{ }^{* * * *} \mathrm{p}<0.001$.

markers for breast cancer (31,32). IHC analysis (Fig. 3A) showed that expression of $\mathrm{Ki}-67$ in the tumor tissues was significantly inhibited after treatment. Concomitantly, we detected the concentration of CA15-3 in serum using mouse CA15-3 ELISA kit. Results demonstrated that the CA15-3 level in the control group was evidently higher than levels in the other groups $(\mathrm{p}<0.05)$ (Fig. 3B). These results demonstrated that $\mathrm{XN}$ restrained the growth of breast cancer cells in the mouse model.

$X N$ activates CTL responses in the mouse model. CTL responses are very important for cellular immunity, and it is associated with Th1 polarization (19). The ratio of $\mathrm{CD}^{+} / \mathrm{CD} 25^{+}$ lymphocytes was detected by flow cytometry. As shown in Fig. 4A and D-a, XN increased the ratio of $\mathrm{CD}^{+} / \mathrm{CD}^{2} 5^{+}$when compared with that noted in the control group. Fig. 4B, C and D-b and -c indicate that expression of perforin and granular enzyme B were also markedly upregulated by treatment with $\mathrm{XN}$ (compared with control group, all p<0.05).

XN promotes the Th1/Th2 balance drift to Th1 polarization in the mouse model. Numerous studies have shown that cancer disrupts the Th1/Th2 balance, and this is known as 'balance shifting' (33-35). IFN- $\gamma$ and IL-4 are pivotal cytokines 
A
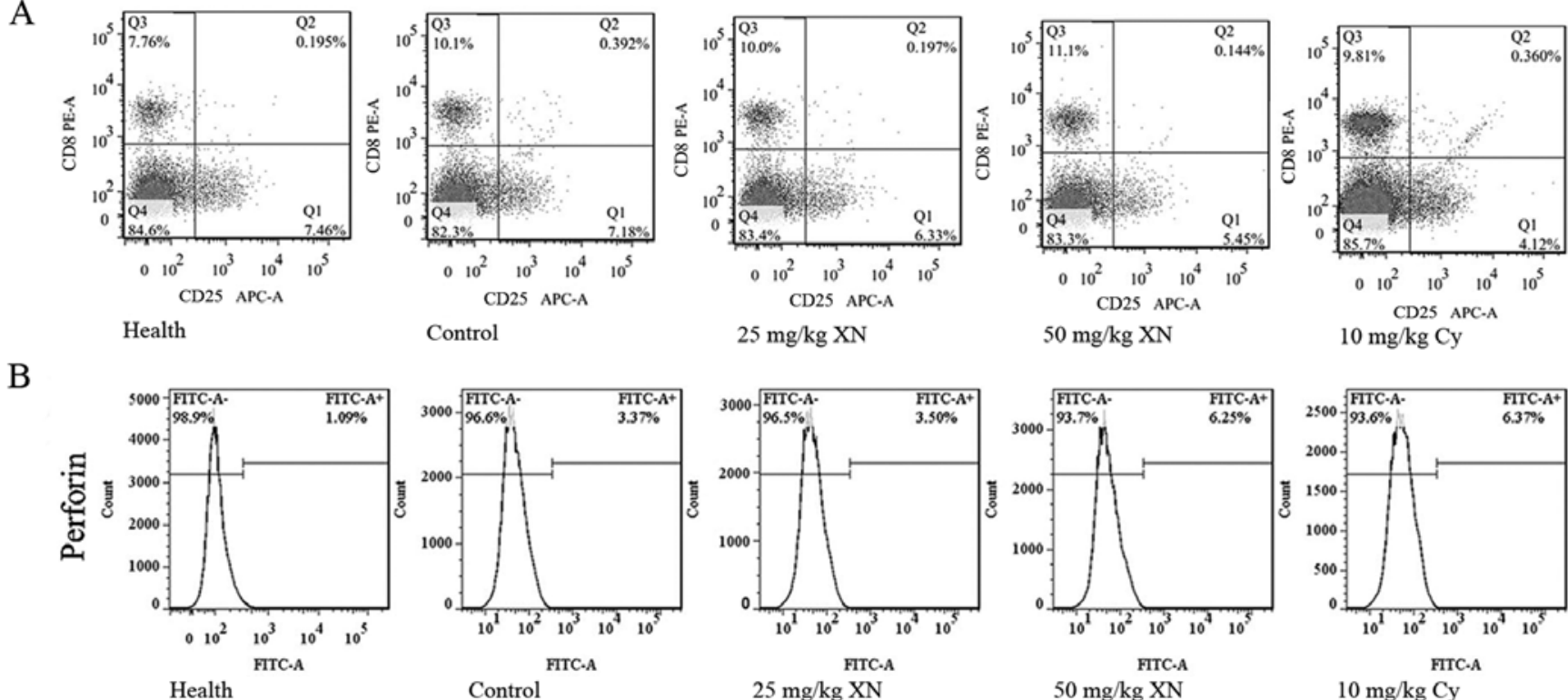

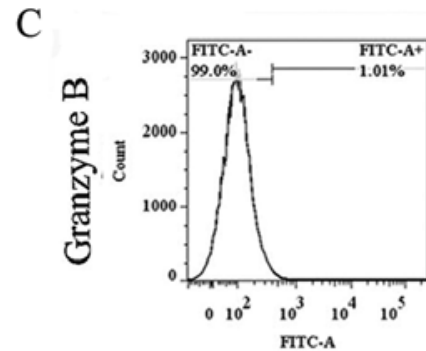

D Health

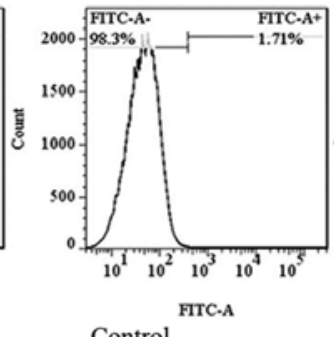

Control

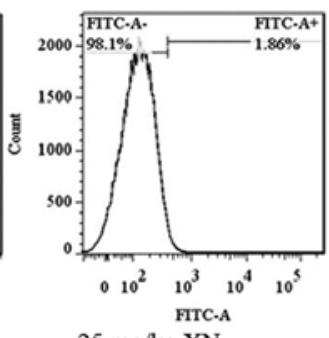

$25 \mathrm{mg} / \mathrm{kg} \mathrm{XN}$

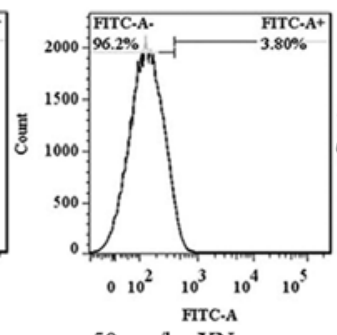

$50 \mathrm{mg} / \mathrm{kg} \mathrm{XN}$

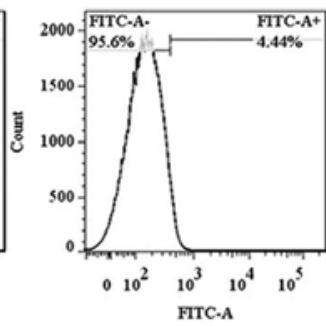

$10 \mathrm{mg} / \mathrm{kg} \mathrm{Cy}$
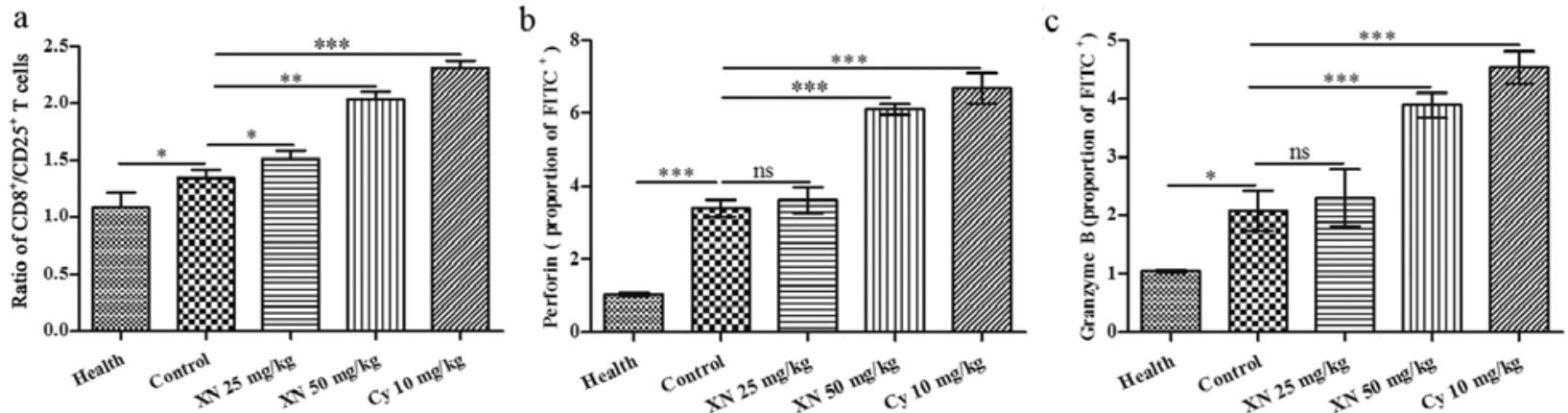

Figure 4. Effect of xanthohumol (XN) on cytotoxic T lymphocyte (CTL) responses in the mouse model. Isolated T lymphocytes by lymphocyte separation medium from the spleen; each experiment was repeated at least three times and the counted cell number was 200,000 in each sample. (A-C) Detection of CD $8^{+} /$ $\mathrm{CD} 25^{+}$, perforin and granzyme B by flow cytometry. (D) Statistical analysis of the results of flow cytometry, including (a) the ratio of CD ${ }^{+} / \mathrm{CD} 25^{+}$; (b) perforin and (c) granzyme B. ${ }^{*} \mathrm{p}<0.05,{ }^{* *} \mathrm{p}<0.01,{ }^{* * *} \mathrm{p}<0.001$. ns, not significant.

which are produced by Th1 and Th 2 cells, respectively. We investigated Th1 and Th2 cytokines in serum by ELISA kit. As shown in Fig. 5, expression of Th1 cytokines IL-2 and IFN- $\gamma$ was markedly enhanced; in contrast, expression of Th2 cytokines, (including IL-4 and IL-10) was evidently weakened after XN therapy $(\mathrm{p}<0.05)$. Fig. 6A and B show the flow cytometric analysis of Th1 $\left(\mathrm{CD}^{+} \mathrm{IFN}-\gamma^{+}\right)$and Th2 $\left(\mathrm{CD} 4^{+} \mathrm{IL}^{+}\right)$cells, respectively. Fig. 6C-a and -b indicates that the percentage of Th1 cells was significantly increased, while the percentage of Th2 cells was markedly decreased after treatment with $50 \mathrm{mg} / \mathrm{kg} \mathrm{XN}$ (compared with control group, $\mathrm{p}<0.05$ ). Fig. $6 \mathrm{C}-\mathrm{c}$ indicates that the ratio of Th1/Th2 in the $50 \mathrm{mg} / \mathrm{kg}$ XN-treated group was significantly increased compared with the control group $(\mathrm{p}<0.05)$.
$X N$ activates STAT4, a pivotal factor in Th1 differentiation, in the mouse model. Based on the above results, $\mathrm{XN}$ regulated the Th1/Th2 balance drifting to Th1, indicating that there may be merit in exploring the mechanisms of the balance drifting. We examined expression levels of key proteins in Th1 and Th2 development with western blotting and IHC, respectively. As shown in Fig. 7 the expression of T-bet and p-STAT4 were markedly enhanced, while GATA-3 was significantly weakened $(\mathrm{p}<0.05)$. Meanwhile, $\mathrm{p}$-STAT6 did not obviously change $(\mathrm{p}>0.05)$. Simultaneously, the results of IHC corroborated those of western blotting. The above results indicated that STAT4, mediating Th0 differentiate to Th1, may be involved in the influence of the Th1/Th2 balance by $\mathrm{XN}$. 

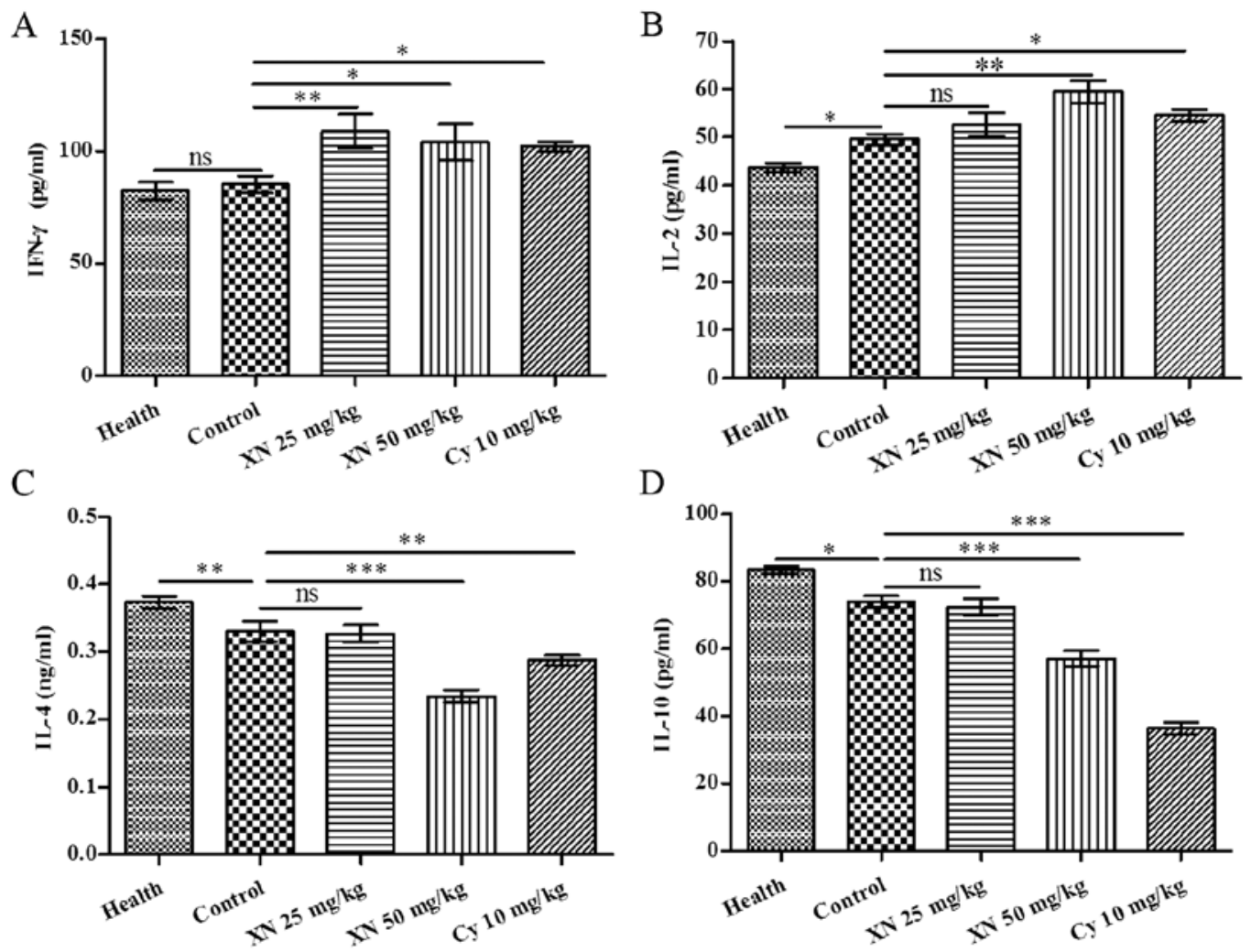

Figure 5. Effect of xanthohumol (XN) on Th1/Th2 cytokines in the mouse model. (A-D) Th1 and Th2 cytokines were detected using ELISA in serum, including IFN- $\gamma$, IL-2, IL-4 and IL-10. ${ }^{*} \mathrm{p}<0.05,{ }^{* *} \mathrm{p}<0.01,{ }^{* * * *} \mathrm{p}<0.001$. ns, not significant.
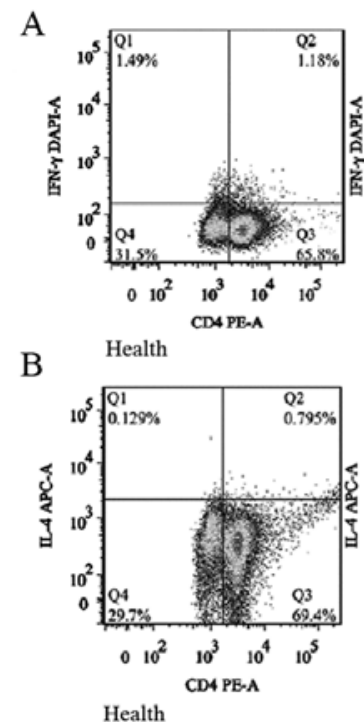

$\mathrm{C}$ Health

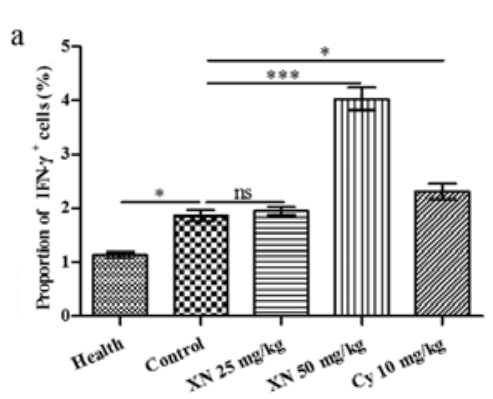

Control

Control
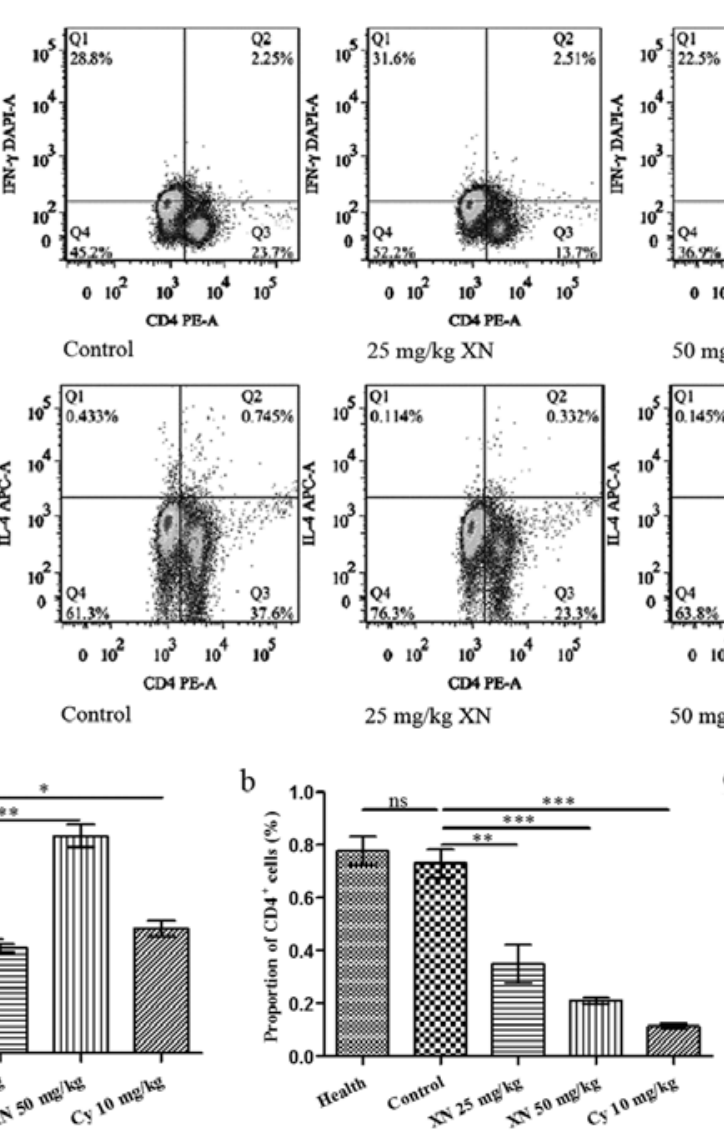

$25 \mathrm{mg} / \mathrm{kg} \mathrm{XN}$

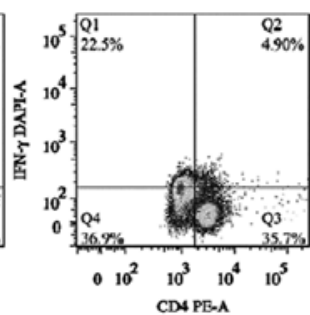

$50 \mathrm{mg} / \mathrm{kg} \mathrm{XN}$

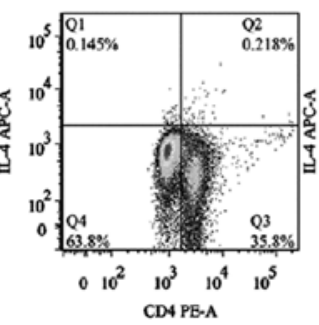

$50 \mathrm{mg} / \mathrm{kg} \mathrm{XN}$

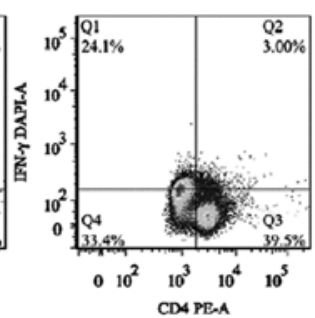

$10 \mathrm{mg} / \mathrm{kg} \mathrm{Cy}$

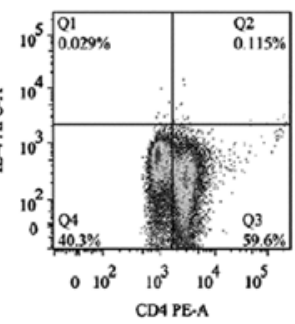

$10 \mathrm{mg} / \mathrm{kg} \mathrm{Cy}$

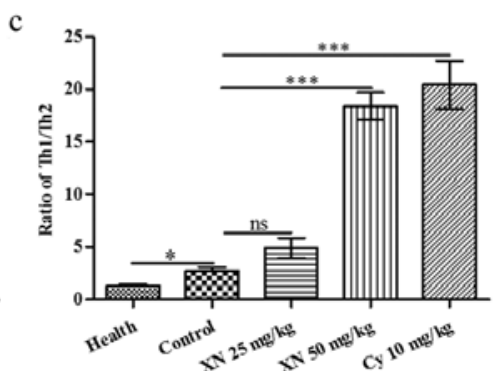

Figure 6. Effect of xanthohumol (XN) on Th1/Th2 balance in the mouse model. Isolated T lymphocytes by lymphocyte separation medium from the spleen. Each experiment was repeated at least three times and the counted cell number was 200,000 in each sample. (A and B) Detection of Th1 and Th2 cells by flow cytometry. (C) Statistical analysis of (a) Th1 and (b) Th2 cell proportions and (c) the ratio of Th1/Th2. ${ }^{*} \mathrm{p}<0.05$, $^{* *} \mathrm{p}<0.01,{ }^{* * *} \mathrm{p}<0.001$. ns, not significant. 

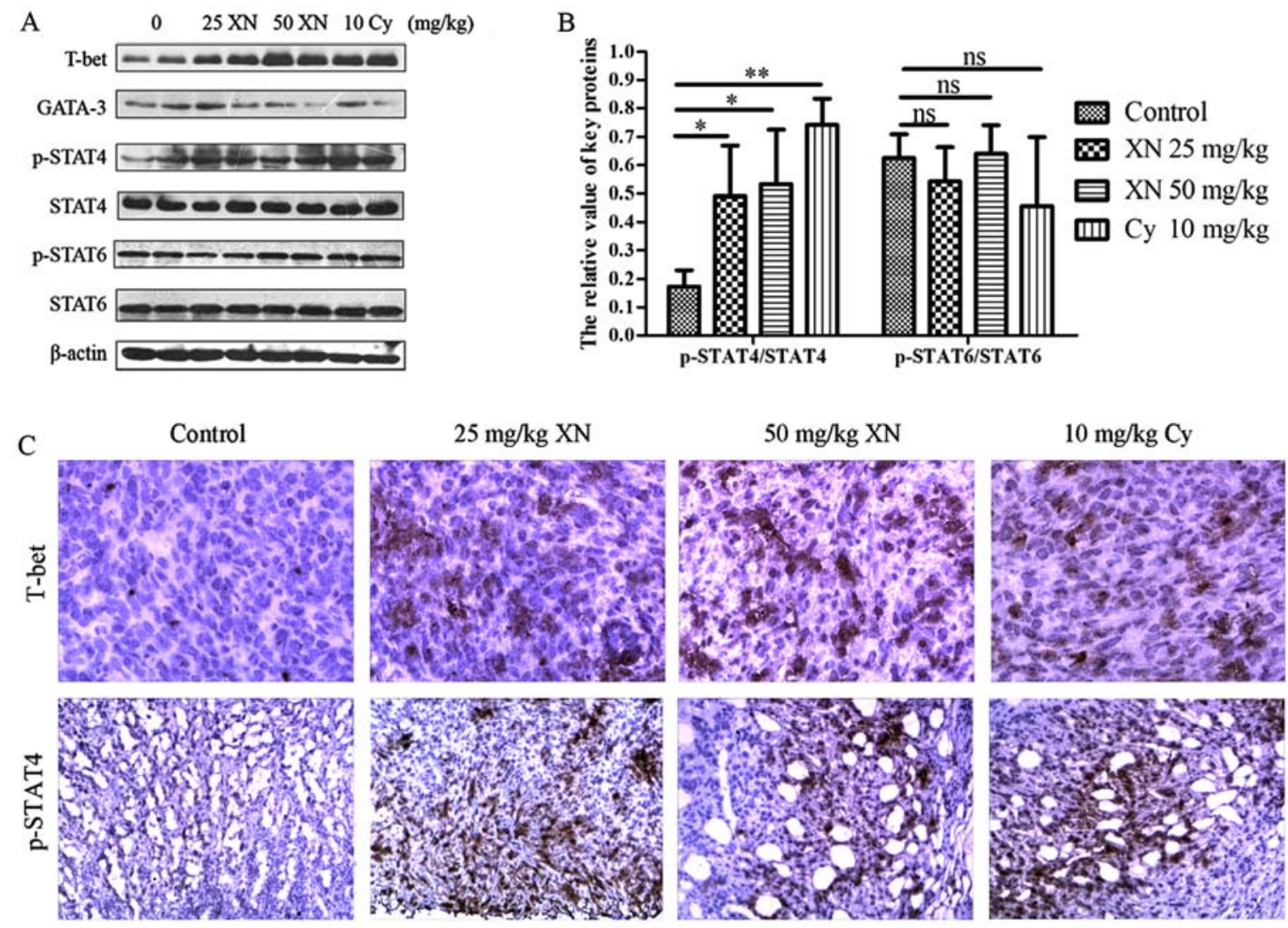

Figure 7. Effect of xanthohumol (XN) on expression of Th1/Th2-specific transcription factor T-bet, GATA-3 and p-STAT4 and p-STAT6 in tumor tissues. Tumors were removed, and a portion was frozen at $-80^{\circ} \mathrm{C}$ for protein extraction, and another portion was fixed in buffered formalin for IHC. (A) Western blotting of T-bet, GATA-3, p-STAT4 and p-STAT6 in tumor tissue. (B) Quantitative analysis of expression of p-STAT4 and p-STAT6. (C) IHC of T-bet and p-STAT4 in tumor tissue (magnification, $\mathrm{x} 20$ ). ${ }^{*} \mathrm{p}<0.05,{ }^{* *} \mathrm{p}<0.01 . \mathrm{ns}$, not significant.

\section{Discussion}

Th1/Th2 is closely related to a variety of tumors $(33,36,37)$, and it is also one of the hotspots in immunological therapy of malignancy. In the present study, we demonstrated that xanthohumol (XN), a prenylflavonoid found in the hop plant Humulus lupulus, inhibited tumor growth, enhanced Th1 cytokines and promote Th1/Th2 balance drifting to Th1 population in a breast cancer mouse model. Consistent with a previous study, both $\mathrm{XN}$ and combination therapy (ginseng polysaccharides and dendritic cells) caused an increase in the Th1 population (35). In addition, we observed the underlying mechanisms and found that XN activated STAT4 when Th1 cytokines were upregulated.

XN exhibits many biological properties, including antiobesity (38), anti-hyperlipidemia (39), anti-angiogenic (40), pro-apoptosis and modulation of autophagy (8), anti-invasion (41) and anti-inflammatory activities (42). A previous study concerning the safety profile of $\mathrm{XN}$ revealed that $1,000 \mathrm{mg} / \mathrm{kg} \mathrm{XN}$ feeding did not impair the function of major organs and homoeostasis in the mouse (43). Choi et al (44) suggested that $\mathrm{XN}$ may increase IL-2 production in T cells, which means that $\mathrm{XN}$ may promote an immune response mediated by Th1. Cho et al (45) revealed that XN inhibits IL-12, which indirectly promotes differentiation of Th1 in the immune system by activating transcription (STATs) molecules. In physiological condition, Th1 and Th2 maintain a relative dynamic balance, but when organisms are in a morbid state, the balance may be broken (18). These results raise a potential link between $\mathrm{XN}$ and Th1/Th2, and this appears to be a field worthy of investigation.

The cytotoxic T lymphocyte (CTL) is a type of crucial effector cell in cellular immunity, and plays an important role in the process of antitumor immunology. $\mathrm{CD} 8^{+} \mathrm{CTL}$ exists as a form of CTL-P, which is a non-activated precursor cell in vivo. CTL-Ps are activated by related-antigen and in assistance of Th1 cytokines, and then develop into mature CTLs (30). Liao et al (19) reported that relative $\mathrm{CD} 8^{+} / \mathrm{CD} 25^{+}$ cells were evidently increased following $\mathrm{Th} 2$ to $\mathrm{Th} 1$ transition in the tumor microenvironment. Liu et al (46) showed that the ratio of $\mathrm{CD}^{+} / \mathrm{CD} 25^{+} \mathrm{T}$ cells was significantly increased when the CTLs were activated by $\mathrm{CoCl}_{2}$ in the $4 \mathrm{~T} 1$ cell line. The present study demonstrated that the ratio of $\mathrm{CD}^{+} / \mathrm{CD} 25^{+}$was observably increased in the $\mathrm{T}$ lymphocyte subset in the spleen in breast cancer-bearing mice; meanwhile, an increase in expression of perforin and granular enzyme was also detected. The above results revealed that CTLs were activated.

The function of Th1 and Th2 cells depends on the secretion of different cytokines. To investigate the effects of XN on Th1/Th2 cytokines, we detected serum levels of cytokines associated with Th1 and Th2 using ELISA kits. Our findings showed that XN significantly increased expression of Th1 cytokines (including IL-2 and IFN- $\gamma$ ), and decreased levels of Th2 cytokines (including IL-4 and IL-10). This is understandable due to the fact that Th1 and Th2 are mutually inhibitory (47). Moreover, we detected the ratio of Th1/Th2 cytokines by flow 
cytometry and found that the ratio was markedly elevated by $\mathrm{XN}$. Similar studies have been reported in a variety of tumors. Sparano et al (48) reported that patients with advanced head and neck squamous cell carcinoma apparently have a decrease in Th1 cytokines compared with less advanced patients, while an increase in Th2 cytokines. Liao et al (19) found that combination therapy promoted cytokine transition from Th2 to Th1 in the tumor microenvironment. The above results indicate that an imbalance of Th1/Th2 cytokines is extensively observed in many types of tumors and most usually in advanced cancers.

To confirm the potential mechanism of XN on Th1/Th2 cytokines further, we determined expression of key factors in the pathway of Th1 and Th2 differentiation. Th0 cells differentiate to Th1 and Th2 cells proportionally in the physiological condition (29). In addition, it has been proved that activated STAT4 and STAT6 play an irreplaceable role in the pathway of Th0 differentiation to Th1 and Th2, respectively (49). However, T-bet and GATA-3 are also pivotal in the two pathways $(50,51)$. Chen et al $(52)$ reported that CpG-ODN (cytosine-phosphorothioate-guanine containing oligodeoxynucleotide), a strong Th1 adjuvant, decreased the expression of GATA-3 and STAT6 by activating T-bet, STAT1 and STAT4 in a lung cancer mouse model. Guo et al (29) found that mangiferin may be attributed to the modulation of Th1/ Th2 cytokine imbalance via inhibiting the STAT6 signaling pathway in an asthmatic mouse model. In the present study, the results showed that XN enhanced expression of T-bet, while reduced GATA-3. Furthermore, STAT4 was activated by XN, but there was no significant effect on the level of p-STAT6. This suggests that STAT4 may play a positive role in the regulation of $\mathrm{XN}$ on Th1/Th2 cytokines.

In summary, the present study illustrated that $\mathrm{XN}$ enhanced the Th1 immunity response, which appears to be more effective in mediating anticancer function. In addition, a pivotal molecule in the differentiation of Th1, STAT4, was concurrently activated, but the underlying mechanisms are still unclear. These results demonstrated that $\mathrm{XN}$ may be a promising candidate for breast cancer treatment. Nevertheless, further study must be carried out in different mouse cancer models and molecular docking is required to confirm the active site of $\mathrm{XN}$.

\section{Acknowledgements}

This study was supported by the Science and Technology Support Projects of Gansu Province (no. 1104FKCA123; http:// www.gsstc.gov.cn). The funders had no role in study design, data collection and analysis, decision to publish, or preparation of the manuscript.

\section{References}

1. DeSantis CE, Lin CC, Mariotto AB, Siegel RL, Stein KD, Kramer JL, Alteri R, Robbins AS and Jemal A: Cancer treatment and survivorship statistics, 2014. CA Cancer J Clin 64: 252-271, 2014.

2. Wang GL and Lin ZB: The immunomodulatory effect of lentinan. Yao Xue Xue Bao 31: 86-90, 1996 (In Chinese).

3. Lei LS and Lin ZB: Effect of Ganoderma polysaccharides on $\mathrm{T}$ cell subpopulations and production of interleukin 2 in mixed lymphocyte response. Yao Xue Xue Bao 27: 331-335, 1992.

4. Zhang Q and Lin Z: Study on antitumor activity and mechanism of Ganoderma polysaccharides B. Zhongguo Zhong Xi Yi Jie He Za Zhi 19: 544-547, 1999 (In Chinese).
5. Jiang W, Zhao S, Xu L, Lu Y, Lu Z, Chen C, Ni J, Wan R and Yang L: The inhibitory effects of xanthohumol, a prenylated chalcone derived from hops, on cell growth and tumorigenesis in human pancreatic cancer. Biomed Pharmacother 73: 40-47, 2015.

6. Venè R, Benelli R, Minghelli S, Astigiano S, Tosetti F and Ferrari N: Xanthohumol impairs human prostate cancer cell growth and invasion and diminishes the incidence and progression of advanced tumors in TRAMP mice. Mol Med 18: 1292-1302, 2012.

7. Yoshimaru T, Komatsu M, Tashiro E, Imoto M, Osada H, Miyoshi Y, Honda J, Sasa M and Katagiri T: Xanthohumol suppresses oestrogen-signalling in breast cancer through the inhibition of BIG3-PHB2 interactions. Sci Rep 4: 7355, 2014.

8. Kunnimalaiyaan S, Sokolowski KM, Balamurugan M, Gamblin TC and Kunnimalaiyaan M: Xanthohumol inhibits Notch signaling and induces apoptosis in hepatocellular carcinoma. PLoS One 10: e0127464, 2015.

9. Kunnimalaiyaan S, Trevino J, Tsai S, Gamblin TC and Kunnimalaiyaan M: Xanthohumol-mediated suppression of Notch1 signaling is associated with antitumor activity in human pancreatic cancer cells. Mol Cancer Ther 14: 1395-1403, 2015.

10. Benelli R, Venè R, Ciarlo $\mathrm{M}$, Carlone $\mathrm{S}$, Barbieri $\mathrm{O}$ and Ferrari N: The AKT/NF- $\kappa \mathrm{B}$ inhibitor xanthohumol is a potent anti-lymphocytic leukemia drug overcoming chemoresistance and cell infiltration. Biochem Pharmacol 83: 1634-1642, 2012.

11. Fowler DH: Rapamycin-resistant effector T-cell therapy. Immunol Rev 257: 210-225, 2014.

12. Xu W, Celeridad M, Sankar S, Webb DR and Bennett BL: CC-4047 promotes Th1 cell differentiation and reprograms polarized human Th2 cells by enhancing transcription factor T-bet. Clin Immunol 128: 392-399, 2008.

13. Szabo SJ, Kim ST, Costa GL, Zhang X, Fathman CG and Glimcher LH: A novel transcription factor, T-bet, directs Th1 lineage commitment. Cell 100: 655-669, 2000.

14. Zhu J, Yamane H, Cote-Sierra J, Guo L and Paul WE: GATA-3 promotes Th2 responses through three different mechanisms: Induction of Th2 cytokine production, selective growth of Th2 cells and inhibition of Th1 cell-specific factors. Cell Res 16: 3-10, 2006.

15. Ouyang W, Löhning M, Gao Z, Assenmacher M, Ranganath S, Radbruch A and Murphy KM: Stat6-independent GATA-3 autoactivation directs IL-4-independent Th2 development and commitment. Immunity 12: 27-37, 2000.

16. Kurata H, Lee HJ, O'Garra A and Arai N: Ectopic expression of activated Stat6 induces the expression of Th2-specific cytokines and transcription factors in developing Th1 cells. Immunity 11: 677-688, 1999.

17. Oh S and Hwang ES: The role of protein modifications of T-bet in cytokine production and differentiation of T helper cells. $\mathrm{J}$ Immunol Res 2014: 589672, 2014.

18. Kidd P: Th1/Th2 balance: The hypothesis, its limitations, and implications for health and disease. Altern Med Rev 8: 223-246, 2003.

19. Liao D, Luo Y, Markowitz D, Xiang R and Reisfeld RA: Cancer associated fibroblasts promote tumor growth and metastasis by modulating the tumor immune microenvironment in a 4T1 murine breast cancer model. PLoS One 4: e7965, 2009.

20. Hong M, Jiang Z and Zhou YF: Effects of thermotherapy on Th1/Th2 cells in esophageal cancer patients treated with radiotherapy. Asian Pac J Cancer Prev 15: 2359-2362, 2014.

21. Yoshino S, Yoshimura K, Suzuki N, Iida M, Yoshida S, Maeda Y, Maeda K, Hazama S and Oka M: Immunoregulatory effects of PSK on the Th1/Th2 balance and regulatory T-cells in patients with colorectal cancer. Gan To Kagaku Ryoho 37: 2234-2236, 2010 (In Japanese).

22. Romagnani S, Maggi E and Del Prete G: An alternative view of the Th1/Th2 switch hypothesis in HIV infection. AIDS Res Hum Retroviruses 10: iii-ix, 1994.

23. Crane IJ and Forrester JV: Th1 and Th2 lymphocytes in autoimmune disease. Crit Rev Immunol 25: 75-102, 2005.

24. Matsuzaki J, Tsuji T, Imazeki I, Ikeda $H$ and Nishimura T: Immunosteroid as a regulator for Th1/Th2 balance: Its possible role in autoimmune diseases. Autoimmunity 38: 369-375, 2005.

25. Zhihong Sun CZ, Feng Liu, et al: Inhibition of breast cancer cell survival by Xanthohumol via modulating Notch signaling pathway in vivo and in vitro. Oncology Letters: 15585229/12/2015.

26. Kast RE: Ribavirin in cancer immunotherapies: Controlling nitric oxide augments cytotoxic lymphocyte function. Neoplasia $5: 3-8$, 2003. 
27. Matar P, Rozados VR, Gervasoni SI and Scharovsky GO Th2/Th1 switch induced by a single low dose of cyclophosphamide in a rat metastatic lymphoma model. Cancer Immunol Immunother 50: 588-596, 2002.

28. Naito S, von Eschenbach AC, Giavazzi R and Fidler IJ: Growth and metastasis of tumor cells isolated from a human renal cell carcinoma implanted into different organs of nude mice. Cancer Res 46: 4109-4115, 1986.

29. Guo HW, Yun CX, Hou GH, Du J, Huang X, Lu Y, Keller ET, Zhang J and Deng JG: Mangiferin attenuates TH1/TH2 cytokine imbalance in an ovalbumin-induced asthmatic mouse model. PLoS One 9: e100394, 2014.

30. Ubukata H, Motohashi G, Tabuchi T, Nagata H, Konishi S and Tabuchi T: Evaluations of interferon- $\gamma /$ interleukin- 4 ratio and neutrophil/lymphocyte ratio as prognostic indicators in gastric cancer patients. J Surg Oncol 102: 742-747, 2010.

31. Gao J, Zhang Q, Xu J, Guo L and Li X: Clinical significance of serum miR-21 in breast cancer compared with CA153 and CEA. Chin J Cancer Res 25: 743-748, 2013.

32. Tan QX, Qin QH, Yang WP, Mo QG and Wei CY: Prognostic value of Ki67 expression in HR-negative breast cancer before and after neoadjuvant chemotherapy. Int J Clin Exp Pathol 7: 6862-6870, 2014

33. Shurin MR, Lu L, Kalinski P, Stewart-Akers AM and Lotze MT: Th1/Th2 balance in cancer, transplantation and pregnancy. Springer Semin Immunopathol 21: 339-359, 1999.

34. Feili-Hariri M, Falkner DH and Morel PA: Polarization of naive $\mathrm{T}$ cells into Th1 or Th2 by distinct cytokine-driven murine dendritic cell populations: Implications for immunotherapy. J Leukoc Biol 78: 656-664, 2005.

35. Ma J, Liu $\mathrm{H}$ and Wang X: Effect of ginseng polysaccharides and dendritic cells on the balance of Th1/Th2 Thelper cells in patients with non-small cell lung cancer. J Tradit Chin Med 34: 641-645, 2014

36. Saxena R and Kaur J: Th1/Th2 cytokines and their genotypes as predictors of hepatitis B virus related hepatocellular carcinoma. World J Hepatol 7: 1572-1580, 2015.

37. Hong CC, Yao S, McCann SE, Dolnick RY, Wallace PK, Gong Z Quan L, Lee KP, Evans SS, Repasky EA, et al: Pretreatment levels of circulating Th1 and Th2 cytokines, and their ratios, are associated with ER-negative and triple negative breast cancers. Breast Cancer Res Treat 139: 477-488, 2013.

38. Kiyofuji A, Yui K, Takahashi K and Osada K: Effects of xanthohumol-rich hop extract on the differentiation of preadipocytes. J Oleo Sci 63: 593-597, 2014.

39. Casaschi A, Maiyoh GK, Rubio BK, Li RW, Adeli K and Theriault AG: The chalcone xanthohumol inhibits triglyceride and apolipoprotein B secretion in HepG2 cells. J Nutr 134: 1340-1346, 2004.
40. Costa R, Rodrigues I, Guardão L, Lima JQ, Sousa E, Soares R and Negrão R: Modulation of VEGF signaling in a mouse model of diabetes by xanthohumol and 8-prenylnaringenin: Unveiling the angiogenic paradox and metabolism interplay. Mol Nutr Food Res 61: doi: 10.1002/mnfr.201600488, 2017.

41. Sasazawa Y, Kanagaki S, Tashiro E, Nogawa T, Muroi M, Kondoh Y, Osada $\mathrm{H}$ and Imoto $\mathrm{M}$ : Xanthohumol impairs autophagosome maturation through direct inhibition of valosin-containing protein. ACS Chem Biol 7: 892-900, 2012.

42. Lee IS, Lim J, Gal J, Kang JC, Kim HJ, Kang BY and Choi HJ: Anti-inflammatory activity of xanthohumol involves heme oxygenase-1 induction via NRF2-ARE signaling in microglial BV2 cells. Neurochem Int 58: 153-160, 2011.

43. Dorn C, Bataille F, Gaebele E, Heilmann J and Hellerbrand C: Xanthohumol feeding does not impair organ function and homoeostasis in mice. Food Chem Toxicol 48: 1890-1897, 2010.

44. Choi JM, Kim HJ, Lee KY, Choi HJ, Lee IS and Kang BY: Increased IL-2 production in T cells by xanthohumol through enhanced NF-AT and AP-1 activity. Int Immunopharmacol 9: 103-107, 2009.

45. Cho YC, You SK, Kim HJ, Cho CW, Lee IS and Kang BY: Xanthohumol inhibits IL-12 production and reduces chronic allergic contact dermatitis. Int Immunopharmacol 10: 556-561, 2010.

46. Liu Z, Lv D, Liu S, Gong J, Wang D, Xiong M, Chen X, Xiang R and Tan X: Alginic acid-coated chitosan nanoparticles loaded with legumain DNA vaccine: Effect against breast cancer in mice. PLoS One 8: e60190, 2013.

47. Mosmann TR and Sad S: The expanding universe of T-cell subsets: Th1, Th2 and more. Immunol Today 17: 138-146, 1996.

48. Sparano A, Lathers DM, Achille N, Petruzzelli GJ and Young MR: Modulation of Th1 and Th2 cytokine profiles and their association with advanced head and neck squamous cell carcinoma. Otolaryngol Head Neck Surg 131: 573-576, 2004.

49. Pernis AB and Rothman PB: JAK-STAT signaling in asthma. J Clin Invest 109: 1279-1283, 2002.

50. Mowen KA and Glimcher LH: Signaling pathways in Th2 development. Immunol Rev 202: 203-222, 2004.

51. Chang HC, Han L, Goswami R, Nguyen ET, Pelloso D, Robertson MJ and Kaplan MH: Impaired development of human Th1 cells in patients with deficient expression of STAT4. Blood 113: 5887-5890, 2009.

52. Chen J, Wang Y, Mei Z, Zhang S, Yang J, Li X, Yao Y and Xie C: Radiation-induced lung fibrosis in a tumor-bearing mouse model is associated with enhanced type-2 immunity. J Radiat Res 57 : 133-141, 2016. 